\title{
The Evaluation of Tourism Resources and Product Development Research in Yong Deng County along the Da Tong River and Zhuang Lang River Line

\author{
Lu-Cang WANG ${ }^{a}$, Hui-Rong WANG ${ }^{\text {b, }}$
}

College of Geography and Environment Science, Northwest Normal University, Lanzhou 730070, Gansu, China

aWanglc007@nwnu.edu.cn, bwanghuirong505@163.com

*wanghuirong505@163.com

Keywords: Da Tong river, Zhuang Lang river, The evaluation of Tourism Resources, Product development.

\begin{abstract}
Based on the sketched about Yong Deng county along the Da Tong river and Zhuang Lang river line, this study has made the classification and evaluation of the Da Tong river and Zhuang Lang river line, discussed it's tourism resources of abundance and exploitation. Afterwards, analyze the Present situation of tourism products, the results show that there still exist some disadvantages of tourism product development in Yong Deng county along the Da Tong river and Zhuang Lang river line. In order to form the tourism product pedigree of the Da Tong river and Zhuang Lang river line, it should obey the principle of market-oriented, add the current situation of tourism products pay attention to the linkage between different products and blending at the same time.
\end{abstract}

\section{Introduction}

With the development of tourism, Tourism because of its unique characteristics of the industry becomes more and more important in people's life. Yong Deng county along the Da Tong river and Zhuang Lang river line have rich tourism resources, distinctive features, cultural tourism resources accounted for the majority of tourism attractions, tourism development prospects are very broad. But because of the tourism products the lack of a single, so that visitors can directly participate in the activities of experience, attraction is weak, causing passengers do not want to tour for a long time, and the current tourism resources is still at the primary level of development, to be developed. Based on the research of the evaluation of tourism resources and product development inYong Deng county along the Da Tong river and Zhuang Lang river line, can provide the basis for the development of Tourism.

\section{An Overview of Tourism Resources}

\section{Tourism Resources Concept}

Wen-WEI Fu proposed, the tourism resources of tourist attraction is the natural and social scene and factors. That is, the tourism resources refers to the objective existence has been the development and utilization of undeveloped utilization, are all natural can attract people to develop tourism activities, human activities and the general term for a variety of their products formed in different periods of [1].

Tian-Yuan LI thinks, those who can create attractive natural factors on tourist environment, social factors or any other factors, can constitute the tourism resources[2]. Therefore, to attract tourists visiting the attraction of tourism resources is the source[3].

In this paper, the author believes that tourism resources are the factors that can stimulate the tourists to visit and experience in a certain area[4]. 


\section{The concept of tourism products}

The definition of tourism products mainly from two angles, experience and overall view. The first factor view from the perspective of tourists, that tourists spend some time and energy costs in exchange for a one-time tourist experience. Second kinds of views from the destination, think tour operators with tourism facilities, tourism attractions and traffic to tourists can meet all the needs of the tourism service activities for tourism products[5].

\section{Analysis of Current Tourism Resources}

Yongdeng county is located in central Gansu Province, the county area of 6090 square kilometers of territory[6]. This paper mainly studies the evaluation of tourism resources and product development in Yong Deng county along the Da Tong river and Zhuang Lang river line. Datong River is a tributary of the Huangshui River, 54 kilometers in length, the valley area of 1331.1 square kilometers. The Zhuanglang river is a tributary of the Yellow River, 94.5 kilometers in length, watershed area of 2335 square kilometers. The Zhuanglang River along the lush, pleasant climate, thick loess, suitable for living, with has a long history and splendid culture, has the very high research value.

\section{Key Tourism Resources}

There are so many important tourism resources in Yong Deng county along the Da Tong river and Zhuang Lang river line. Such as known as "fairy Valley" 4A National Forest Park Tulugou, Shiping mountain, Gada temple, Qinglong park, founded in the Western Han Dynasty emperor shenjue two years (60 BC), the remaining Ming Hongzhi years built a large Buddhist temple that is Hongchengzi[7], a famous tourist attraction Fenghuangshan, Yongdeng Taoist activities resort Renshou mountain, eight of Yongdeng's "Xuan Mao Zhu Tuo" Buddhist of Feng Shui treasure Zhutuo mountain[8], Babao Forest Nature Reserve, located in Datong River west "Babao River" area famous scenic tourist area of Liancheng Xisigou, Yaoshuigou, The four batch of national key cultural relics protection units, relatively well preserved buildings of Ming and Qing Dynasty Lutusi Yamen[9], the Sixth Batch of national key cultural relics protection units Gan'en temple, the earliest Tibetan Buddhist monastery Xianjiao temple in Liancheng area, the provincial cultural relics protection units Haide temple, Qingliang temple, Hongmen temple, what the rare Taoist architectural relics in Northwest China is Leitan[10], cultural relics protection units at the county level in Bell Tower and Drum Tower, Wenchang temple, Shanshan hall, "Yindaruqin Project " known as Gansu Dujiangyan[11].

\section{Classification of Current Tourism Resources}

Classification of tourism resources is the basis of tourism resources investigation and evaluation of tourism resources, but also the objective needs of understanding, rational planning, development and utilization of tourism resources[12]. According to the national "tourism resource classification, investigation and evaluation"(GB/T18972-2003) standard, through to the status of tourism resources investigation in Yong Deng county along the Da Tong river and Zhuang Lang river line, draw the proportion of the current tourism resources type is shown in fig.1. 


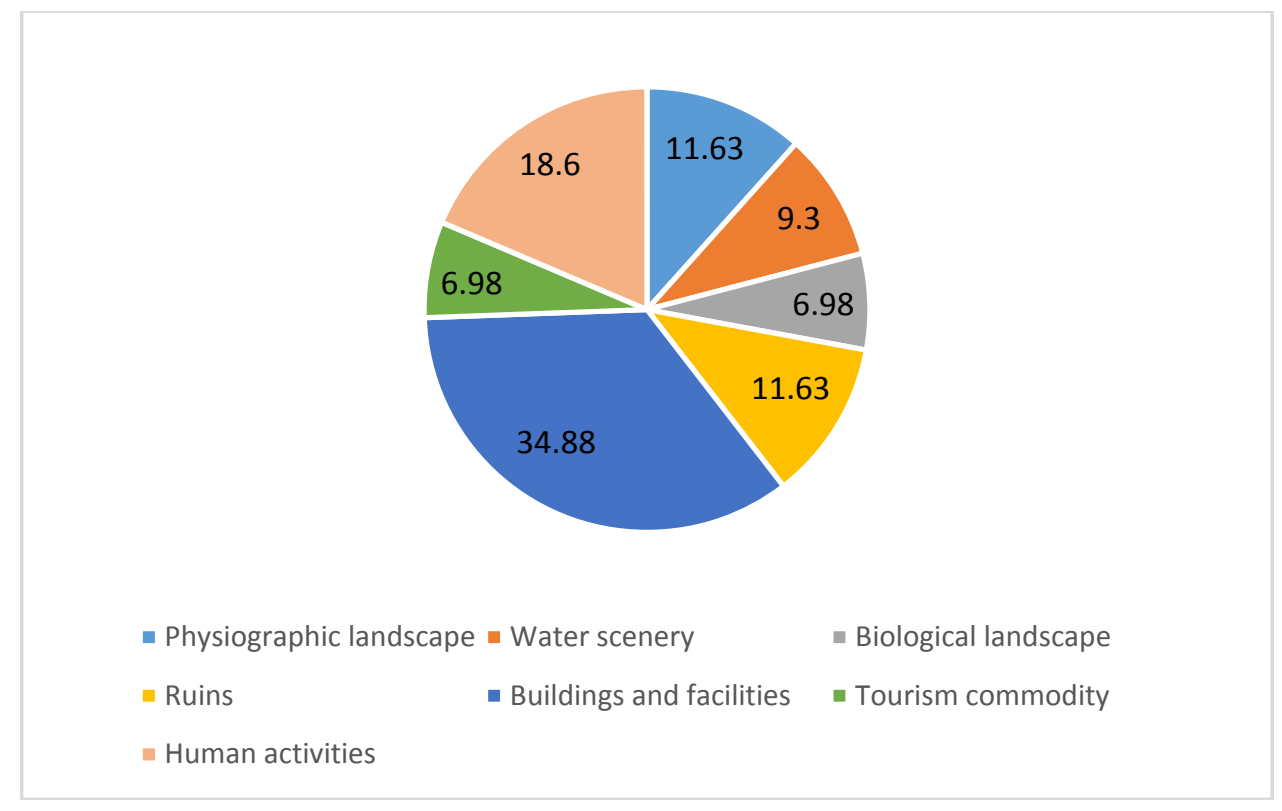

Fig. 1 The proportion of the current tourism resources type

According to Fig.1, statistical classification of core tourism resources in Yong Deng county along the Da Tong river and Zhuang Lang river line as follows, there are 8 main types of tourism resources in the country, including 31 sub classes and 155 basic types, Yongdeng county have 7 main categories, 20 sub categories and 43 basic types. The main class tourism resources accounted for the main class $87.5 \%$, sub category accounted for $64.5 \%$, accounting for basic types $27.7 \%$. On the whole cultural tourism resources are more abundant, main building and facilities tourism resources, Followed by cultural tourism activities, the landscape and Ruins in the proportion of the same, tourist commodities at least.

\section{The Evaluation of Current Tourism Resources}

\section{Classification and Evaluation of Tourism Resources}

According to the "tourism resources classification, investigation and evaluation of the national standard"(GB/T18972-2003), and considering the actual development and evaluation, constructed by three categories of evaluation index about the resource value, tourism resources influence and additional evaluation. Constitute the tourism resources evaluation system of historical and cultural value, recreational value, rare degree the scale, and richness, whether to preserve the integrity, reputation, appropriate travel period, the overall image, environmental factors of 10 evaluation factors[13].

\section{Evaluation Results}

In accordance with the "tourism resources classification, investigation and evaluation of the national standard"(GB/T18972-2003) of the single tourism resource evaluation index and classification criteria, a single tourist resource is divided into five levels[14].

According to the evaluation results, Tulugou National Forest Park, Lutusi Yamen, Gada temple, Miaoyin temple is four level of tourism resources, they have high grade, unique culture and strong advantage, they are representative of resources, and will attract a lot of visitors. Two tourism resources are relatively more, become the basis of tourism resources, is the future development of star tourism support.

Resources evaluation, although the academic research value is high, but the audience area is small, the tourist attraction is insufficient; the tourist resources type is relatively unitary, relative lack of natural resources. 


\title{
Research on Tourism Product Development
}

\author{
Analysis of Current Tourism Products
}

\section{Single Product, Tourism Products is Still the Mainstream}

At present, the main tourism products in Yong Deng county along the Da Tong river and Zhuang Lang river line,such as Tulugou National Forest Park tourism, special tourism as the representative of the Hongcheng town and Liancheng town, in April Eight Buddha Festival on behalf of the special tourism festival. But a single tourism product, a lot of tourist resources in the primary state of development. Leisure, experience and other tourism products are to be further improved.

Therefore, to solve the probllem of single tourism products, should be broaden the width of tourism products, to extend the length of combination of tourism products, supplement leisure tourism and special tourism products. For example, tourism of Tusi culture research, building the Ming Dynasty archaeological tourism, festival tourism of folk custom.

\section{Lack of Integration and Linkage}

Yong Deng county along the Da Tong river and Zhuang Lang river line, tourism project is not integrated, the lack of linkage between the scenic, scenic spot and fail to fully reflect the advantages of resources and complementary advantages. The development of existing products with the same in near area, cause tourism products compete. Tourism development projects are in urgent need of transformation and upgrading, with good resources of many scenic spots development with lower grades, small scale, spotty development, the comprehensive efficiency is not high.

\section{Cultural Experience, Leisure Tourism Products Need To Be Further Developed}

At present, the current layout of tourism products is characterized by scattered development in Yong Deng county along the Da Tong river and Zhuang Lang river line. The main representative of ecological tourism products, folk religious tourism products, tourism site products. Product type is mainly based on low level sightseeing and leisure, the development mode of the static landscape based, should increase the development of leisure tourism products.

\section{Tourism Product Development}

According to the characteristics of tourism resources and the overall framework of tourism development in Yong Deng county along the Da Tong river and Zhuang Lang river line, follow the market oriented principle, development the leisure tourism as the main tourism products, Tusi culture, Historic Site cultural, folk religious tourism and other historical and cultural tourism brand. Ecological leisure travel, green agriculture and rural tourism based the background of folk custom tourism and ecological tourism and leisure tourism and cultural integration, focusing on linkage and blending of different products, constitute the tourism product pedigree of the distinctive characteristics inYong Deng county along the Da Tong river and Zhuang Lang river line.

\section{Development Ideas}

In the short term, tourism is still irreplaceable, tourism is the foundation of Tourism development in Yong Deng county along the Da Tong river and Zhuang Lang river line, at the same time, it also provides a good external environment for the development of tourism products. Based on natural scenery sightseeing, ecological leisure green tourism, agricultural sightseeing tourism, ruins tourism product system. By improving the quality of tourism products, increase the added value, the rational allocation of "Eat, Live, Walk, Travel, Shopping, Entertainment", improve the comprehensive benefit. To improve the traffic network system and tourism interpretation system, improve the fit of scenic spots clothing service quality. In view of the strong affinity of tourism products, combined with holiday, sports, culture and other tourism development. Optimize the geographical combination, improve the overall level of tourism products. 
Cultural experience tourism products is the focus of its development in Yong Deng county along the $\mathrm{Da}$ Tong river and Zhuang Lang river line. The organic integration of cultural tourism development and natural development. In the traditional static display based on the use of modern audio-visual technology, increase the dynamics of cultural tourism products and activities to participate, strengthen the construction of interpretation system. Professionalism is as important as popularity, increasing the audience of cultural products. As far as possible to retain the original culture, to protect the embody the historical and realistic environment to give visitors the real experience. In the new market situation, re understanding of local historical and cultural resources, dig the context and form the experience from simple sightseeing to the depth of products Change.

Special tourism product is the supplement and extension of the cultural experience and the two tourism products in Yong Deng county along the Da Tong river and Zhuang Lang river line, but also enhance the attractiveness and competitiveness of the market of auxiliary products. And the diversification of tourism products and the realization of the goal of innovation lies in the construction and development of special tourism product group. Relying on the advantages of cultural experience and leisure tourism resources, the elements of tourism resources, play product innovation enthusiasm of tourism enterprises, and to capture market opportunities. From the point of view of time and space change and the connotation of quality and tourism, focus on the development of cultural experience and festivals, sports and other tourism projects, increase the diversity of tourism products, promote the development of new tourism products.

\section{Development Content}

According to the above mentioned development ideas, supplement the Rampart Ruins Park Tourism , The Silk Road Tourism, Datong River Waterfront Tourism, cultural tourism research Tusi, Ming Dynasty architecture ancient archaeological tourism, cutltural experience tour, graduation season tourism, festival tourism of folk custom, self drive tourism, religious tourism.

The Silk Road Tourism in Hongcheng town is full of ancient silk culture as the carrier. Tell the history story and enrich historical landscape, integrate into tourism experience activities. Through the comprehensive management of water environment of Zhuanglang River and the development of the Qingliang temple, integrate into the Silk Road culture and landscape construction sequence of the Buddhist culture. In the Silk Road cultural performances and other forms around the Silk Road cultural experience, Buddhist cultural experience, Buddhist regimen, health tourism product positioning, the integration of the surrounding mountains, valley resources, create religious worship, Buddhist culture exchanges, lay health resort, rural areas such as supporting functions in one area.

Leisure tourism is Urban park construction in Chengguan town. Developing cultural and leisure tourism on Qinglong mountain, Shiping mountain, Zhutuo mountain, Renshou monument. The town of Hongcheng town and Liancheng town as the core, two towns linkage, increase rural leisure tourism vacation with Kushui town as the key function. And the integration of the surrounding villages and rose planting planting base, the formation of modern agricultural industrial park and the rose garden, rose base to build a tourism, cultural experience, theme restaurants, family entertainment and tourist attractions, the surrounding villages in the development of rural leisure vacation. The cool ecological environment for the foundation in Tulugou and Zhulingou, introduction of forest leisure resort and the function of sports leisure vacation.Focus on sports leisure, leisure construction of return to nature and the cool summer vacation resort.

\section{Summary}

This article through to the tourism resources investigation in Yong Deng county along the Da Tong river and Zhuang Lang river line, classification and evaluation of existing resources, find it is rich in tourism resources. The majority of tourism resources in the primary state, the lack of tourism resources led to product type single. It is the lack of integration and linkage, led directly to the tourist experience is poor and the problem of scenic spots less attractive. The tourism product 
development is the core and key to the development of scenic spots, tourism resources determine the direction and purpose of tourism product development. so the process of tourism development in Yong Deng county along the Da Tong river and Zhuang Lang river line must take tourism resources based on the status quo, the product is promoted and developed on the basis of the current situation, focusing on the development of cultural tourism, at the same time, taking into account the study of tourism, experience tourism and other new tourism models, and enhance market competitiveness.

\section{Acknowledgment}

This research is funded by the Natural Science Foundation of China (41261042).

\section{Reference}

[1] Wen-WeiFU. Evaluation and development of tourism resources[M]. Hangzhou University Press, 1994.

[2] Cui-Ling BAI. Introduction to Tourism[M]. Zhejiang University Press,2013.

[3] Guan-Yao LI, Hai-Hong Liu. Tourism Course[M]. Peking University Press,2005.

[4] Hua QUAN. Development and Management of Tourism Resources[M]. Tourism Education Press,2006.

[5] Bi-Hu WU. Principles of Tourism planning[M].China Tourism Press,2010.

[6] Ze-Dong HUO. Yongdeng County[M]. Gansu Culture Press, 2011.

[7] Wen-Zhang XUE. The history of the Hongchengtown[M]. Gansu Culture Press, 2010.

[8] Cun-Rui SHI. Yongdeng culture[M]. China Zhigong Publishing House, 2012.

[9] Xiu-Wen ZHAO.About Historical Cultural Resources and Tourism Development of Chieftain Lu in Liancheng of Yongdeng Gansu[D]. Northwest Normal University, 2007.

[10]Cheng-Xuan YIN. The Present Situation and Protection Countermeasures of Lu Tusi Yamen[D]. Northwest Normal University, 2013.

[11]He-Hou KANG. The Yellow River Biography[M]. Gansu Culture Press, 2007.

[12]Ling-Qiang ZHOU. Management of Tourist Attractions[M]. Zhejiang University Press, 2006.

[13] Xiao-Zu HE. The classification of tourism resources of national standard "the investigation and evaluation of a number of amendments " [J]. Tourism Science, 2006, 20 (5): 62-67.

[14]Xiao-Dong SU. Research on urban tourism resources development planning[D]. Harbin Institute of Technology,2008. 